\title{
Implementasi Sistem eLearning di Universitas Sam Ratulangi
}

\author{
Arie S. M. Lumenta ${ }^{1}$ \\ ${ }^{1}$ Program Studi Teknik Elektro, F-TEKNIK, UNSRAT Manado, arie.lumenta@ unsrat.ac.id
}

\begin{abstract}
Abstrak
Sistem eLearning dibangun untuk menunjang proses kegiatan belajar mengajar. Sistem ini dapat digunakan sebagai pendamping proses belajar mengajar konvensional, serta dilaksanakan secara paralel atau bersamaan. Dalam tulisan ini akan dibahas tentang implementasi sistem eLearning di Universitas Sam Ratulangi. Pada tahap awal implementasi sistem eLearning yang dibangun, sebagian besar hanya dimanfaatkan oleh dosen pengajar sebagai media distribusi materi perkuliahan. Aplikasi yang digunakan untuk implementasi sistem eLearning adalah Moodle. Hanya ada sedikit dosen yang memanfaatkan sistem ini bukan hanya sekedar sebagai media distribusi materi kuliah, tetapi juga sebagai sarana untuk berkomunikasi dengan mahasiswa di luar waktu kuliah dan melakukan manajemen tugas kuliah secara online serta mengadakan evaluasi atau kuis secara online.
\end{abstract}

Kata kunci: CMS, Moodle, Sistem eLearning

\section{Implementation of eLearning System at the University of Sam Ratulangi}

\section{Abstract}

eLearning system built to support the learning process. This system can be used as a companion to conventional teaching and learning process, and implemented in parallel or concurrently. In this paper will discuss the implementation of eLearning system at Sam Ratulangi University. In the early stages of implementation of eLearning systems are built, mostly only used by lecturers as media distribution of lecture material. Application used for the implementation of eLearning system is Moodle. There are very few lecturers who take advantage of this system is not just as a medium for the distribution of course material, but also as a means to communicate with students outside of class time and perform management assignment online lectures as well as an evaluation or online quiz.

Keywords: CMS, , Moodle, eLearning System

\section{Pendahuluan}

Universitas Sam Ratulangi adalah institusi pendidikan tinggi yang mengemban tugas melaksanakan tri darma pendidikan tinggi yaitu, pendidikan, penelitian dan pengabdian pada masyarakat. Darma pendidikan dilakukan dengan melaksanakan kegiatan atau proses belajar mengajar. Proses belajar mengajar dilaksanakan dengan cara, dosen melakukan tatap muka dengan mahasiswa di kelas pada waktu yang sudah ditentukan. Di dalam kelas, dosen menjelaskan materi kuliah dan memberi tugas serta melakukan evaluasi atau kuis. Metode atau cara seperti ini disebut sebagai metode konvensional.

Perkembangan teknologi jaringan komputer dan internet telah turut membawa perubahan dalam proses belajar mengajar. Banyak sistem dan aplikasi baru yang tercipta sebagai dampak dari perkembangan teknologi jaringan komputer dan internet. Salah satunya adalah sistem eLearning.

Sistem eLearning adalah metode yang relatif baru yang dibuat untuk menciptakan suatu lingkungan proses belajar mengajar yang menyerupai atau mirip dengan lingkungan proses belajar mengajar yang sudah kita kenal selama ini.

Sistem ini membutuhkan teknologi internet atau setidaknya jaringan komputer untuk dapat diimplementasikan. Sistem eLearning ini dapat memudahkan bagi dosen untuk mengatur perkuliahannya yakni distribusi materi kuliah, peserta kuliah, tugas, kuis dan manajemen nilai. Infrastruktur perangkat keras jaringan komputer dan fasilitas internet yang dimiliki oleh Universitas Sam Ratulangi memenuhi syarat untuk mengimplementasikan sistem eLearning. 
eLearning adalah sebuah proses pembelajaran mandiri yang difasilitasi dan didukung melalui pemanfaatan teknologi jaringan komputer dan internet. Model eLearning secara umum dapat dibagi ke dalam kategori 2 besar yaitu eLearning statis dan eLearning dinamis. Hal terpenting yang diperlukan dalam membangun sebuah sistem eLearning adalah interaksi antara pengguna dan komputer.

eLearning memiliki filosofi sebagai berikut :

- eLearning merupakan penyampaian informasi komunikasi, pendidikan, pelatihan secara online

- eLearning menyediakan seperangkat alat yang dapat memperkaya nilai belajar secara konvensional sehingga dapat menjawab tantangan perkembangan globalisasi

- eLearning tidak menggantikan model belajar konvensional di dalam kelas, tetapi memperkuat melalui pengayaan konten dan pengembangan teknologi pendidikan

- Kapasitas mahasiswa amat bervariasi tergantung pada bentuk isi dan cara penyampaiannya. Makin baik keselarasan konten dan alat penyampaian dengan gaya belajar, maka akan lebih baik kapasitas mahasiswa yang pada gilirannya akan memberi hasil yang lebih baik.

\section{Metode}

Sistem eLearning yang diimplementasikan di Universitas Sam Ratulangi memanfaatkan Aplikasi Course Management System yang bersifat open source dan gratis serta dapat didownload secara bebas yakni Moodle.

Moodle dapat merubah sebuah media pembelajaran kedalam bentuk web. Aplikasi ini memungkinkan dosen membuat ruang kelas digital dan mahasiswa dapat masuk kedalam ruang kelas digital tersebut untuk mengakses materi-materi pembelajaran. Dengan menggunakan Moodle, dosen dapat membuat materi pembelajaran, kuis, jurnal elektronik dan lain-lain.

Aplikasi Moodle yang digunakan untuk implementasi sistem adalah Moodle versi 2.6.4+. Untuk dapat menginstal aplikasi ini dengan baik dibutuhkan beberapa perangkat lunak lainnya yaitu: Web Server, Database dan PHP.

Web server yang digunakan adalah Apache versi 2.2, dengan Database MySQL versi 5.1 serta PHP versi 5.3.3. Seluruh perangkat lunak tersebut dinstal diatas sistem operasi Linux CentOS 6.5 Final. Semua perangkat lunak digunakan bersifat freeware atau gratis dan dapat di-download secara bebas dari internet.

Perangkat keras yang digunakan untuk instalasi sistem adalah sebuah komputer server dengan spesifikasi sebagai berikut: HP Proliant ML350G6, Processor Intel Xeon E5606 @ 2.13GHz, Memory 8GB DDR3, dan HDD 1TB SATA 7200rpm.

Setelah proses instalasi selesai, selanjutnya dilakukan pengaturan DNS Server Sistem eLearning ke alamat: elearning.unsrat.ac.id.

\section{Hasil dan Pembahasan}

Untuk mengakses sistem eLearning diperlukan komputer yang terhubung ke internet atau jaringan kampus Unsrat. Selanjutnya buka aplikasi browser dan ketikkan pada lokasi address alamat: elearning.unsrat.ac.id. Tampilan pada browser selanjutnya akan seperti pada gambar 1.

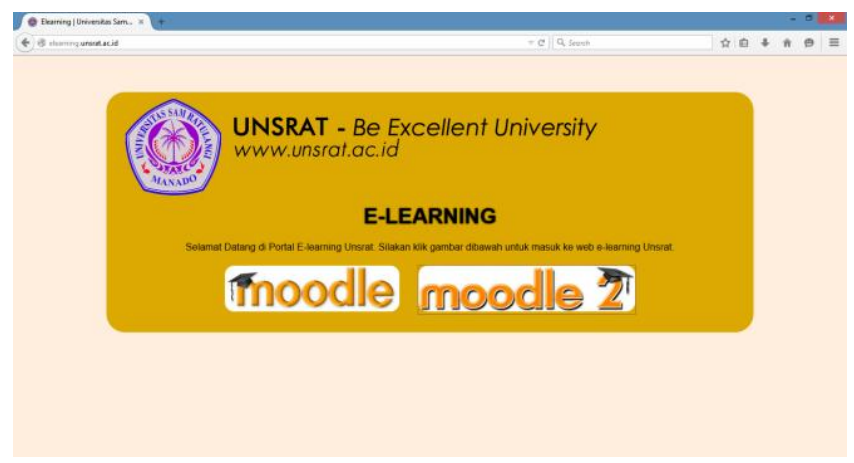

Gambar 1. Tampilan awal eLearning 
Ada dua pilihan Moodle yang tersedia yakni Moodle dan Moodle 2. Moodle dapat dikatakan adalah tempat eksperimen awal. Moodle menggunakan aplikasi Moodle versi 1.9, yang saat ini sudah tidak digunakan.

Adapun sistem eLearning yang ada adalah pada Moodle 2. Saat Moodle 2 di-klik akan muncul tampilan seperti pada gambar 2 .

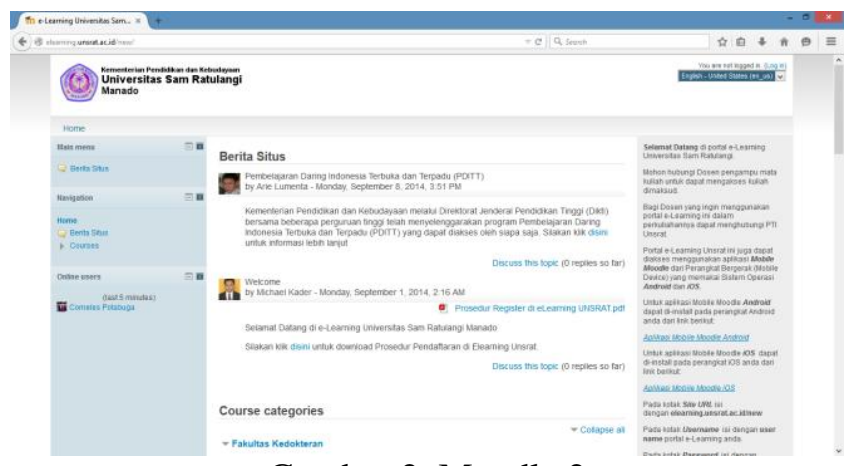

Gambar 2. Moodle 2

Matakuliah yang ada pada sistem eLearning dikategorikan dalam Fakultas, Pasca Sarjana dan Lain-lain / Umum.

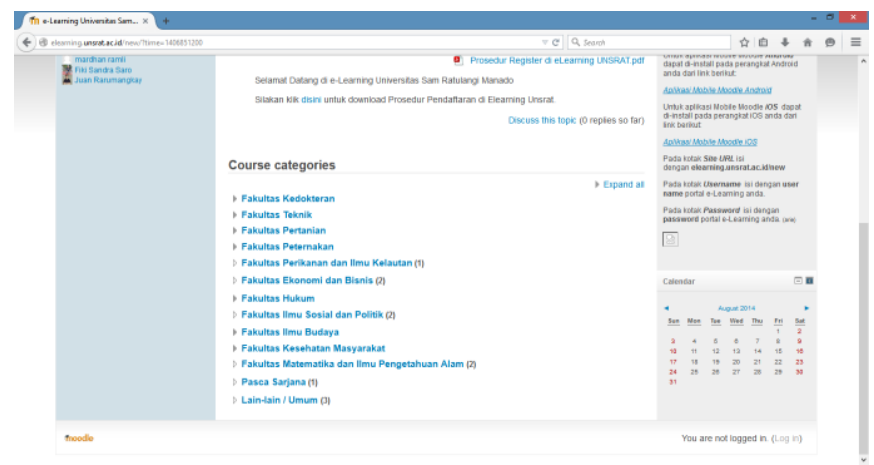

Gambar 3. Kategori Matakuliah

Selanjutnya dari kategori Fakultas masih dikelompokkan lagi dalam Semester, yakni Semester I sampai Semester VIII.

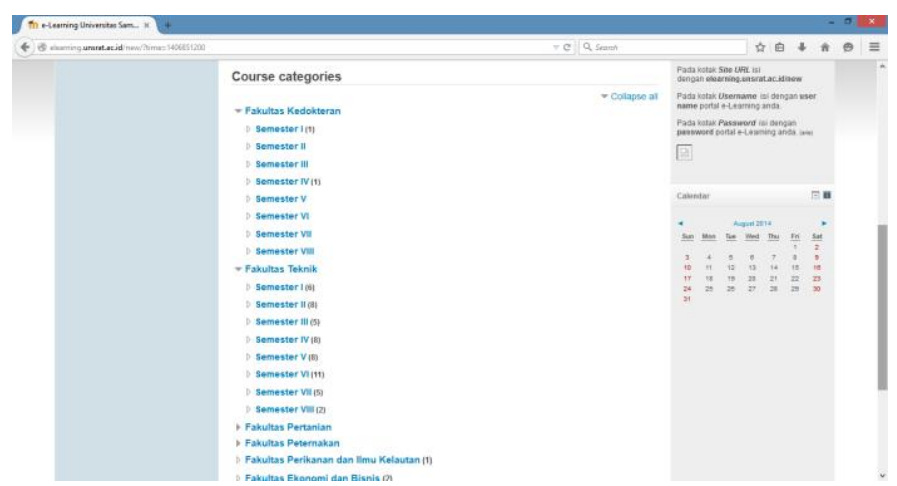

Gambar 4. Pengelompokan Semester

Sampai tulisan ini dibuat jumlah matakuliah yang ada di sistem eLearning Universitas Sam Ratulangi adalah seperti yang ditunjukkan Tabel 1. 
Tabel 1. Jumlah matakuliah

\begin{tabular}{|r|l|l|}
\hline No. & Fakultas & Jumlah Matakuliah \\
\hline 1. & Kedokteran & 2 \\
\hline 3. & Peknik & 53 \\
\hline 4. & Peternakan & 7 \\
\hline 5. & Perikanan dan Ilmu kelautan & 1 \\
\hline 6. & Ekonomi dan Bisnis & 1 \\
\hline 7. & Hukum & 2 \\
\hline 8. & Ilmu Sosial dan Politik & 2 \\
\hline 9. & Ilmu Budaya & 2 \\
\hline 10. & Kesehatan Masyarakat & 3 \\
\hline 11. & Matematika dan Ilmu Pengetahuan Alam & 2 \\
\hline 12. & Pasca Sarjana & 2 \\
\hline 13. & Lain-lain / Umum & 3 \\
\hline \multicolumn{2}{|c|}{ Total } & 81 \\
\hline
\end{tabular}

Dari Tabel 1 terlihat, Fakultas Teknik memiliki jumlah matakuliah terbanyak yang ada di sistem eLearning. Bila dilihat lebih dalam lagi, jumlah matakuliah terbanyak di Fakultas Teknik didominasi oleh dosen dari Program Studi Teknik Elektro dan Program Studi Teknik Informatika.

Usaha yang pernah dilakukan untuk memperbanyak jumlah matakuliah pada sistem eLearning Universitas Sam Ratulangi adalah dengan memberi insentif kepada dosen yang membuat matakuliah yang diampunya untuk ditempatkan di sistem eLearning. Namun usaha ini juga kurang berhasil.

Beberapa kendala yang dihadapi dosen untuk dapat membuat kelas matakuliah di eLearning adalah: Banyak dosen yang tidak/belum tahu menggunakan Moodle, masih sedikit dosen yang mampu membuat materi kuliah dalam bentuk digital, dan tidak banyak dosen yang mengakses sistem eLearning Universitas Sam Ratulangi.

Dari keseluruhan jumlah matakuliah yang terdapat pada sistem eLearning, sebagian besar hanya menjadikan sistem eLearning sebagai media untuk menyebarluaskan materi kuliah kepada peserta kuliah. Dalam hal ini sistem eLearning yang ada tidak atau belum dimanfaatkan secara optimal. Fitur yang disediakan oleh aplikasi sistem eLearning itu sendiri dapat memudahkan dosen untuk mengorganisir kuliah yang diampunya.

Mahasiswa juga memiliki peran yang besar pada pelaksanaan sistem eLearning. Sebagian besar mahasiswa hanya masuk di sistem eLearning pada awal saja yakni pasa saat mendaftar untuk menjadi peserta kuliah. Setelah ini hanya sedikit mahasiswa yang mengakses sistem eLearning secara kontinu. Hal ini disebabkan karena pada saat masuk pertama kali, mahasiswa segera mendownload seluruh materi kuliah yang ada. Keadaan ini terjadi karena dosen juga jarang mengupdate kuliahnya.

Hanya ada sedikit dosen yang memanfaatkan ssistem eLearning dengan optimal, yakni manajemen tugas kuliah secara online dan melakukan evaluasi/kuis secara online dengan menyediakan bank soal serta berinteraksi dengan mahasiswa menggunakan aplikasi Moodle.

Sistem eLearning yang dibangun di Universitas Sam Ratulangi juga dapat diakses menggunakan perangkat bergerak (komputer tablet dan smart phone) yang menggunakan sistem operasi Android dan iOS, dengan terlibih dahulu menginstal aplikasi Moodle Mobile yang disediakan khusus untuk Android maupun iOS.

\section{Penutup}

Implementasi sistem eLearning di Universitas Sam Ratulangi secara teknis berhasil dilakukan, tetapi dalam pemanfaatannya kurang optimal. Masih banyak dosen pengampu matakuliah yang belum bisa menempatkan matakuliah yang diampunya pada sistem eLearning.

Dibutuhkan pelatihan khusus penggunaan aplikasi Moodle kepada para dosen agar memiliki ketrampilan untuk menempatkan matakuliah pada sistem eLearning. 
5. Daftar Pustaka

[1] https://moodle.org/

[2] https://www.apache.org/

[3] http://www.mysql.com/

[4] http://www.centos.org/

[5] http://php.net/ 